\title{
Factors Influencing the Turnover Intention of Nurses in Small and Medium Hospitals
}

\author{
Mi Young Moon ${ }^{1}$, Seung Hee Han² \\ 1 Student, Dept. Nursing, Gwangju University, Korea, jullym@hanmail.net \\ 2 Professor, Dept. Nursing, Gwangju University, Korea, shhanj @hanmail.net \\ Corresponding Author: SeungHee Han
}

\begin{abstract}
This study is a descriptive research to investigate the effect of verbal abuse experience, burnout and job satisfaction on turnover intention of nurses in small and medium hospitals. The subjects of this study were 233 nurses working in small and medium sized hospitals with over 150 beds and under 300 beds in G City. Data from structured questionnaire was collected from October 15 to October 30, 2019 SPSS Win 24.0 software was used to calculate real numbers, percentage, and to analyze with Pearson's correlation coefficient, and multiple regression. Turnover intentions were positively correlated with experiences of verbal abuse by doctor, by nurse and by patient or guardian. It also positively correlated with exhaustion and negatively correlated with job satisfaction. The factors positively influencing turnover intention were experience of verbal abuse by doctors, and burnout. Job satisfaction affected them negatively. The magnitude of influence was in the order of job satisfaction, burnout, and verbal abuse experience by doctors. The results of this study exhibited that most nurses experienced the verbal violence. The experience of verbal violence decreased the job satisfaction of nurses and increased the intention of burnout and turnover. Therefore, attention should be paid to the experience of verbal abuse for nurses, and the patterns of occurrence of verbal violence should be analyzed and prevented. In addition, there is a great need for systematic strategy development and counter measures that can promote job satisfaction by creating a safe working environment and reduce the intention of burnout and turnover.
\end{abstract}

Keywords: Small and Medium Hospitals, Verbal Abuse Experience, Burnout, Job Satisfaction, Intention to Turn.

\section{Introduction}

Hospitals are strengthening the quality of medical care as patients' rights and demands for medical services increase. Hospital organizations are interacting with each other with members of various occupations[1]. The nursing organization, which accounts for $40-50 \%$ of the hospital's workforce, continuously cares for patients 24 hours a day, and is in a position that greatly affects the competitiveness and productivity of hospitals by providing quality and quality nursing care[2]. Nurses play a pivotal role in providing medical services within the hospital organization, and they are a large organization that accounts for $43.2 \%$ of hospital personnel[3]. Small and medium-sized hospitals continue to increase the rate of nurse turnover due to poor working conditions and lack of welfare compared to advanced general hospitals, and the resulting shortage of nurses is a very serious reality[4]. The turnover rate of nurses in small and medium hospitals is about $23.8 \%$, about twice the average nurse turnover rate, and about three

\footnotetext{
* This article is based on a part of the first author's master's degree dissertation form gwangju University Received: February 04, 2021; $1^{\text {st }}$ Review Result: March 22, 2021; $2^{\text {nd }}$ Review Result: May 11, 2021 Accepted: June 30, 2021
} 
times the turnover rate of nurses with 1,000 beds or more[3].

Nurses are not only highly mentally burdened and stressed due to the nature of their jobs dealing with human life, but are also exposed to conflict, tension, and violence by meeting various people such as patients, guardians, and employees of other departments[5] and violence. The frequency of verbal violence was found to be the highest in type[6]. According to a study on nurses, it was reported that verbal abuse experience had a significant correlation with the nurse's intention to turnover, threatening the nurse's work productivity, self-esteem, and mental health, reducing work ability, and ultimately wanting to quit the job. It is reported that it appears as an important factor in raising the turnover rate by generating thoughts[7]. Burnout lowers job satisfaction, giving nurses a negative self-concept, poor nursing role performance as a professional, negative attitude toward patients, depriving them of professional achievement, and seriously affecting patients and hospital organizations[8]. If nurses, who are major members of the hospital organization, have low job satisfaction, the productivity of the nursing organization decreases, resulting in an increase in the turnover rate, and the turnover causes financial losses at the hospital level[9]. A nurse's turnover requires a lot of time and effort, such as hiring a new nurse for replacement work and education and training for job performance. However, in the case of small and medium-sized hospitals, the supply of nursing manpower, the level of welfare, and the work environment are worse than that of large hospitals, and the psychological burden of nurses feels more than that of large hospitals, which leads to lower job satisfaction, which in turn affects the intention to turnover[10].

Therefore, this study aimed at nurses in all departments working in small and medium-sized hospitals. The purpose of this study was to identify the relationship among the verbal abuse experience experienced by nurses, burnout, job satisfaction, and turnover intention, and identified factors that influence turnover intention.

\section{Research Methods}

\subsection{Research Design}

This study is a descriptive research to confirm the effect of verbal abuse experience, burnout, and job satisfaction of nurses in small and medium hospitals on turnover intention.

\subsection{Research Subjects}

This study targeted nurses working in five small and medium-sized hospitals located in G City, who understood the purpose of the study and responded to the questionnaire. The number of samples required for the study was calculated using the $\mathrm{G}^{*}$ power 3.1.9.2 program. Based on significance level of .05, median effect of .15 , power of .95 , and 15 predictors ( 3 independent variables and 12 general variables), the number of samples for multiple regression analysis was 199. Considering the dropout rate of $20 \%$, a total of 240 questionnaires were distributed and 237 copies were collected, and 233 copies were used for data analysis, excluding 4 copies with insufficient responses.

\subsection{Research Tools}

\subsubsection{General Characteristics}

The general characteristics of this study consist of a total of 12 questions including gender, age, marital status, religion, final academic background, clinical experience, position, work department, work type, job change experience, salary level, and health status. 


\subsubsection{Experience of Verbal Violence}

In this study, verbal violence was revised and supplemented by Koo Ja-gwan[11] based on 17 items for measuring verbal violence experienced by nurses in the operating room developed by Nam Kyungdong[12], and modified to specifically answer the frequency of the question scale. The supplemented tools of Yoo Mi-ok[13] were used.

The tool consists of 13 items in each of 3 areas (doctor, nurse, patient and guardian), and each item is measured on a five-point Likert scale, with one point for 'never', tow points for'very little', and 'normal'. 'Ida' shows three points,'frequently' shows four points, and'very often' shows five points. The higher the score, the more severe the level of verbal abuse. The supplemented tools of Yoo Mi-ok[13] were used. In the study of Yoo Mi-ok[13], Cronbach's $\alpha$ for verbal violence experiences by doctors was .91, Cronbach's $\alpha$ for verbal violence experiences by nurses was .92, and Cronbach's $\alpha$ for verbal violence experiences by patients and caregivers was .93. In this study, Cronbach's $\alpha$ of verbal violence experience by doctors was .94, Cronbach's $\alpha$ of verbal violence experience by nurses was .94 , and Cronbach's $\alpha$ of verbal violence experience by patients and caregivers was .94 .

\subsubsection{Exhaustion}

In this study, a tool developed by Maslach and Jackson[14] to measure the burnout of nurses was used as a measure of the Maslach Burnout Inventory Scale(MBI), which was adapted by Hyeyoon Choi[15] to fit the nurses.

This tool consists of a total of 14 items. For each item, 'not at all' is one point, 'disagree' is two points, 'average' is three points, 'strongly agree' is four points, and before very much' is measured on a fivepoint Likert scale. The higher the score, the higher the degree of burnout of the nurse. In the study of Maslach and Jackson[16], Cronbach's $\alpha$ was .76, in the study of Hyeyun Choi[15], Cronbach's $\alpha$ was .84, and in this study, Cronbach's $\alpha$ was .96.

\subsubsection{Job Satisfaction}

To measure job satisfaction in this study, a tool modified and supplemented by Yoon Jong-suk[17] was used for the Minnesota Satisfaction Questionaire(MSQ) developed by Weiss, Dawis, England, and Lofguist[18]. This tool consists of a total of 19 items, and the sub-factors of job satisfaction are classified into operational, work, personnel, and human relations factors.

Each item is measured on a five-point Likert scale with one point for 'not at all', two points for 'disagree', three points for 'normal', four points for 'disagree', and five points for 'strongly disagree'. In the study of Jongsook Yoon[17], Cronbach's $\alpha$ was .75 for work, Cronbach's $\alpha$ for management was .71, Cronbach's $\alpha$ for personnel was .69 , and Cronbach's $\alpha$ was .82 for human relations. In this study, Cronbach's $\alpha$ was .79 for work, Cronbach's $\alpha$ for management was .80, Cronbach's $\alpha$ for personnel was .79, Cronbach's $\alpha$ was .83 for human relations, and Cronbach's $\alpha$ for overall verbal abuse experience was .81 .

\subsubsection{Turn Intention}

In this study, the tool for measuring turnover intention was combined with Lawer[19] tool, modified and supplemented by Park Hyeon-sook[20] for nurses developed by Kim Young-ran[21].

This tool consists of 11 items, and each item is measured on a five-point Likert scale with one point for 'not at all', two points for 'not at all', threee points for 'normal', four points for 'yes', and ' A score of 'very much' is indicated, with a higher score indicating a higher intention to leave. In the study of Youngran Kim[21], who developed the tool for nurses, Cronbach's was .84, and in this study, Cronbach's $\alpha$ was .89. 


\subsection{Data Collection Method}

The researcher made a reservation and visited the nursing departments of 5 small and medium-sized hospitals to ask for cooperation through official documents and phone calls to explain the research plan and research purpose. After obtaining research permission and permission to use an independent site for the questionnaire, they visited the nursing unit department and explained in advance that the questionnaire was sensitive such as verbal violence experience, burnout, job satisfaction, and turnover intention. After explaining the purpose of the study, voluntary participation was received.

Data was collected from October 15 to October 30, 2019. The researcher distributed the questionnaire to the subjects in an independent location without a nurse so that the subjects could give honest answers. Subjects were informed that they may stop responding to the survey at any time and that the data collected will be used for this study only.

In addition, a simple gift for participants provided, anonymity is guaranteed, and personal information of specific hospitals or respondents is not evaluated separately. Immediately after filling out the questionnaire, it was placed in an envelope and sealed, and the researcher collected it directly.

\subsection{Ethical Consideration of Research Objects}

Prior to data collection for this study, it was approved by the Bioethics Committee of G University (approval number: 201908-HR-008-01). In the questionnaire used for data collection, the research is conducted with the voluntary participation of the research subjects, and if they do not want to participate, they can withdraw at any time, and the content of the questionnaire contains the content that the questionnaire will not be used for purposes other than the research purpose. In order to ensure anonymity, personally identifiable information was excluded and used in the study. The questionnaire was to be destroyed immediately after the completion of the study to protect the subject's ethical aspects.

\subsection{Data Analysis Method}

The collected data were analyzed using the SPSS Win 24.0 program, and the detailed statistical methods are as follows.

1) In order to understand the characteristics of the subjects, real numbers and percentages were calculated.

2) The correlation between the subject's verbal abuse experience, burnout, job satisfaction, and turnover intention was analyzed by Pearson's Correlation Coefficient.

3) Multiple regression analysis was performed for factors affecting the turnover intention of the subjects.

\section{Results}

\subsection{General Characteristics of Subjects}

The general characteristics of the subjects of this study are as follows[Table 1]. By gender, 222(95.3\%) were female. The most common age was 20-29 with 138(59.2\%), and the most common marital status was $174(74.7 \%)$. As for religion, non-religious people accounted for the most with 157(67.4\%). As for the final educational background, 129 people(53.6\%) had a bachelor's degree or higher, and the total clinical experience was less than 1-5 years with 93 people(39.9\%), followed by 69 people with more than 10 years(29.6\%), 45(19.3\%) less than 5-10 years, and 26(11.2\%) less than 1 year. By position, general nurses had the most with 206(88.4\%), and by working department, surgery had the most with 
105(45.1\%), followed by internal medicine with 38(16.3\%), operating room and outpatient with 22 each $(9.4 \%$ each $)$. As for the type of work, three-shift work was the most common with 157 people(67.4\%). Meanwhile, 118 people(50.6\%) said they had no experience of job turnover. As for the level of salary, 192 people( $82.4 \%$ ) were paid 2 to 2.99 million won the most, followed by 41 people(17.6\%) with 3 million won or more. As for the health status, $125(53.6 \%)$ were healthy and $108(46.4 \%)$ were normal.

[Table 1] General Characteristics ( $\mathrm{N}=233)$

\begin{tabular}{|c|c|c|}
\hline \multicolumn{2}{|c|}{ Characteristics } & $\mathrm{N}(\%)$ \\
\hline \multirow{2}{*}{ Gender } & Female & $222(95.3)$ \\
\hline & Male & $11(4.7)$ \\
\hline \multirow{3}{*}{ Age } & $20-29$ & $138(59.2)$ \\
\hline & $30-39$ & $73(31.3)$ \\
\hline & $40-49$ & $22(9.5)$ \\
\hline \multirow{2}{*}{ Martal tatus } & Single & $174(74.7)$ \\
\hline & Married & $59(25.3)$ \\
\hline \multirow{4}{*}{ Religion } & Christian & $47(20.2)$ \\
\hline & Buddhism & $15(6.4)$ \\
\hline & Catholic & $14(6.0)$ \\
\hline & atheism & $157(67.4)$ \\
\hline \multirow{3}{*}{ Final educational background } & Bachelor of arts & $69(29.6)$ \\
\hline & Bachelor & $35(15.0)$ \\
\hline & Bachelor's degree or higher & $129(55.4)$ \\
\hline \multirow{4}{*}{ Total clinical experience } & Less than 1 year & $26(11.2)$ \\
\hline & 1 year - less than 5 years & 93(39.9) \\
\hline & Less than $5-10$ years & $45(19.3)$ \\
\hline & More than 10 years & $69(29.6)$ \\
\hline \multirow{3}{*}{ Position } & General nurses & $206(88.4)$ \\
\hline & Charge nurse & $13(5.6)$ \\
\hline & Head nurse & $14(6.0)$ \\
\hline \multirow{7}{*}{ Working department } & Internal medicine & $38(16.3)$ \\
\hline & Surgery & $105(45.1)$ \\
\hline & Intensive care unit & $17(7.3)$ \\
\hline & Emergency room & $13(5.6)$ \\
\hline & Surgery & $22(9.4)$ \\
\hline & Outpatient & $22(9.4)$ \\
\hline & Etc & $16(6.9)$ \\
\hline \multirow{2}{*}{ Type of work } & Three-shift work & $157(67.4)$ \\
\hline & Full-time work & $76(32.6)$ \\
\hline \multirow{2}{*}{ Experience of job turnover } & Yes & $115(49.4)$ \\
\hline & No & $118(50.6)$ \\
\hline \multirow{2}{*}{ Level of salary } & 2 to 2.99 million won & $192(82.4)$ \\
\hline & 3 million won over & $41(17.6)$ \\
\hline \multirow[b]{2}{*}{ Health status } & Healthy & $125(53.6)$ \\
\hline & Normal. & $108(46.4)$ \\
\hline
\end{tabular}




\subsection{Correlation between Verbal Abuse Experience and Burnout, Job Satisfaction, and Turnover Intention}

In this study, the correlations among verbal abuse experience, burnout, job satisfaction, and turnover intention were examined, as shown in[Table 2]. The intention to leave was the doctor's experience of verbal abuse $(r=.485, \mathrm{p}<.001)$, the nurse's experience of verbal abuse $(\mathrm{r}=.427, \mathrm{p}<.001)$, and the patient's or guardian's experience of verbal abuse $(\mathrm{r}=.388, \mathrm{p}<.001)$ showed a positive $(+)$ correlation with burnout $(\mathrm{r}=.518, \mathrm{p}<.001)$ and positive $(+)$ job satisfaction $(\mathrm{r}=-.530, \mathrm{p}<.001)$.

[Table 2] Correlation between Verbal Abuse Experience, Burnout, Job Satisfaction, and Turnover Intention $(\mathrm{N}=233)$

\begin{tabular}{|c|c|c|c|c|c|c|}
\hline & \multicolumn{3}{|c|}{ Verbal abuse experience } & \multirow[b]{2}{*}{ Burnout } & \multirow[b]{2}{*}{$\begin{array}{c}\text { Job } \\
\text { satisfaction }\end{array}$} & \multirow[b]{2}{*}{$\begin{array}{l}\text { Turnover } \\
\text { intention }\end{array}$} \\
\hline & $\begin{array}{c}\text { Doctor's } \\
\text { experience of } \\
\text { verbal abuse }\end{array}$ & $\begin{array}{c}\text { Nurse's } \\
\text { experience of } \\
\text { verbal abuse }\end{array}$ & $\begin{array}{l}\text { Patient's or } \\
\text { guardian's } \\
\text { experience of } \\
\text { verbal abuse }\end{array}$ & & & \\
\hline Doctor's experience of verbal abuse & 1 & & & & & \\
\hline Nurse's experience of verbal abuse & $.624 * * *$ & 1 & & & & \\
\hline $\begin{array}{l}\text { Patient's or guardian's experience of } \\
\text { verbal abuse }\end{array}$ & $.341^{* * *}$ & $.395^{* * *}$ & 1 & & & \\
\hline Burnout & $.386^{* * *}$ & $.423 * * *$ & $.525 * * *$ & 1 & & \\
\hline Job satisfaction & $-.263 * * *$ & $-.248 * * *$ & $-.298 * * *$ & $-.319 * * *$ & 1 & \\
\hline Turnover intention & $.485 * * *$ & $.427 * * *$ & $.388 * * *$ & $.518 * * *$ & $-.530 * * *$ & 1 \\
\hline
\end{tabular}

\subsection{Factors Affecting Turnover Intention}

[Table 3] Factors Affecting Turnover Intention ( $\mathrm{N}=233)$

\begin{tabular}{|c|c|c|c|c|c|c|c|}
\hline \multirow{2}{*}{ Division } & \multicolumn{2}{|c|}{$\begin{array}{l}\text { Unnormalized } \\
\text { coefficient }\end{array}$} & \multirow{2}{*}{$\begin{array}{c}\begin{array}{c}\text { Standardization } \\
\text { factor }\end{array} \\
\beta\end{array}$} & \multirow{2}{*}{$\mathrm{t}$} & \multirow{2}{*}{$\mathrm{p}$} & \multicolumn{2}{|c|}{ Collinearity Statistics } \\
\hline & $\mathrm{B}$ & S.E & & & & Tolerance & VIF \\
\hline (Constant) & 3.742 & .364 & & 10.274 & .000 & & \\
\hline $\begin{array}{l}\text { Doctor's experience of verbal } \\
\text { abuse }\end{array}$ & .251 & .066 & .237 & 3.793 & .000 & .585 & 1.710 \\
\hline Nurse's experience of verbal abuse & .072 & .073 & .064 & .995 & .321 & .557 & 1.794 \\
\hline $\begin{array}{c}\text { Patient's or guardian's experience } \\
\text { of verbal abuse }\end{array}$ & .035 & .056 & .037 & .628 & .531 & .673 & 1.485 \\
\hline Burnout & .212 & .047 & .267 & 4.491 & .000 & .642 & 1.557 \\
\hline Job satisfaction & -.649 & .094 & -.355 & -6.896 & .000 & .858 & 1.166 \\
\hline
\end{tabular}

$\mathrm{R} 2=.483$, Adj. $\mathrm{R} 2=.472, \mathrm{~F}=42.417(\mathrm{p}=<.001)$, Durbin-Watson= 1.928

In order to examine the factors affecting the turnover intention of the subjects of this study, multiple 
regression analysis was conducted by inputting independent variables such as verbal abuse experience, burnout, and job satisfaction, and the results are shown in [Table 3]. First, all VIF values were less than 10 , and all tolerance limits were greater than .10, indicating that there is no multicollinearity problem. The explanatory power of the regression model, in which the control and independent variables explain the motive for change, was $48.3 \%$, and the $\mathrm{F}$ value indicating the statistical significance of the regression model was $42.147(\mathrm{p}<.001)$, indicating that this regression model was suitable. Doctors' verbal abuse experience $(\beta=.237, \mathrm{p}<.001)$ and burnout $(\beta=.267, \mathrm{p}<.001)$ still had a positive $(+)$ effect on turnover intention, and job satisfaction ( $\beta=-.355, \mathrm{p}<.001)$ was found to have a negative (-) effect. The magnitude of influence was found in the order of job satisfaction, burnout, and the doctor's verbal abuse experience.

\section{Argument}

This study examines the correlation between verbal abuse experience, burnout, job satisfaction, and turnover intention of nurses in all departments of small and medium-sized hospitals affects turnover intention. The experience of verbal violence had a positive correlation with burnout, which is similar to the results of Heejin Son[22] for nurses and Eunha Jung and Sangeun Oh[23] for emergency room nurses in a previous study. Therefore, there is a need for a plan to reduce the experience of verbal violence or a program to reduce the burnout of verbal violence among nurses in small and medium-sized hospitals. Job satisfaction was found to have a negative correlation with turnover intention, and this was found in a previous study by Gino Kang[24] for nurses in small and medium-sized hospitals, Jonghyun Yang, Gyuho Jeong[25], Miran Kim, Kyungae Seo[8] for general nurses, similar to the results of Jo Haengnan and So Hyang-suk[26] targeting shift-working nurses at tertiary general hospitals. Therefore, in order to improve the job satisfaction of nurses, continuous efforts and management are required to improve working conditions and welfare benefits, and further research is needed on the relationship between job satisfaction and turnover intention.

On the turnover intention of nurses in small and medium hospitals, it was found that the doctor's experience and exhaustion of verbal violence had a positive effect and job satisfaction had a negative effect. This is similar to the study by Oh Eui-jin[7] for general hospital nurses and Park Jeong-nam et al[27]. for outpatient nurses on turnover intention.

As for the experience of verbal violence, it was found that the verbal abuse of patients or guardians was the highest[7], but as a factor influencing the intention to leave, the experience of verbal violence from doctors was found to be the highest factor. Nurses place the highest priority on the value of care that must protect patients or their guardians due to the nature of their jobs, and the perception that patients or guardians are customers of medical care is spreading.

On the other hand, the level of verbal abuse experienced by nurses from doctors is gradually increasing, and the experience of verbal violence experienced by doctors working with them with the common goal of high-quality medical care is increasing. It is thought that the nurse's lower self-esteem and exhaustion affect the intention to leave the job, as the behavior of ignoring them as a subordinate rather than a colleague comes as another shock to the nurse. It is thought that it is necessary to expand awareness, establish an organizational culture, and a series of management systems to establish a cooperative relationship between doctors and nurses.

For this study, only 233 nurses working in five small and medium-sized hospitals located in G city were selected by the convenience expression method. Therefore, caution should be exercised in extending the interpretation of the results of this study to all nurses working in other hospitals across the country, and this point should be supplemented in subsequent studies. Through the results of this study, it was found that most of the nurses experienced verbal violence, and it was found that the experience of verbal violence increased nurse burnout, decreased job satisfaction, and increased turnover intention. 
Through this study, the experience of verbal violence was found to be a factor influencing nurses' turnover intention, so they were interested in the experiences of verbal violence experienced by nurses and analyzed the patterns of occurrence, preventing verbal violence and reducing the frequency of occurrence to make it safer. It is very necessary to develop a systematic strategy and countermeasures that can alleviate burnout by creating a working environment, increase job satisfaction, and reduce turnover intention.

\section{Conclusion}

The most factor among turning intentions were the doctor's experience of verbal abuse, the nurse's experience of verbal abuse, and the patient's or guardian's experience of verbal abuse which showed a positive $(+)$ correlation with burnout and positive $(+)$ job satisfaction with a negative $(-)$ correlation.

The factors affecting turnover intention were doctors' experience of verbal abuse and burnout which were still positive $(+)$ on turnover and job satisfaction was found to have a negative (-) effect. The magnitude of influence was found in the order of job satisfaction, burnout, and the doctor's verbal abuse experience.

As a results of this study, it was found that most of the nurses experienced verbal violence, and it was found that the experience of verbal violence increased the burnout of nurses, decreased job satisfaction, and increased turnover intention. Through this study, the experience of verbal violence was found to be a factor influencing nurses' turnover intention, so they were interested in the experiences of verbal violence experienced by nurses and analyzed the patterns of occurrence, preventing verbal violence and reducing the frequency of occurrence to make it safer. It is very necessary to develop a systematic strategy and countermeasures that can alleviate burnout by creating a working environment, increasing job satisfaction, and reducing turnover intention.

\section{Suggestions}

Based on the results of this study, I would like to make the following suggestions.

Realize the seriousness of verbal violence, and suggest that awareness improvement is necessary to prevent verbal violence and create a positive organizational culture. Suggest development and implementation of professional communication education programs to prevent verbal violence, protect nurses, and cope with verbal violence at the nursing department level in hospitals. At the hospital level, it is suggested to develop a mutual coping manual and to prepare an administrative mechanism to provide a safe working environment in the event of verbal violence in the hospital that affects the burnout of nurses and their intention to leave. A qualitative study that enhances the understanding of nurses' experiences of verbal violence in more depth is suggested.

\section{Acknowledgments}

This Study was conducted by research funds from Gwangju University in 2021.

\section{References}

[1] J. Y. Choi, E. Y. Kim, S. Y. Kim, Effects of Empowerment and Job Satisfaction on Nursing Performance of Clinical Nurses, Journal of Korean Academy of Nursing Administraion, (2014), Vol.20, No.4, pp.426-436, https://doi.org/10.11111/jkana.2014.20.4.426 
[2] E. H. Oh, C. B. Chung, The Effect of Empowerment on Nursing Performance, Job Satisfaction, Organizational Commitment, and Turnover Intention in Hospital Nurses, Journal of Korean Academy of Nursing Administraion, (2011), Vol.17, No.4, pp.391-401, UCI : G704-001792.2011.17.4.013

[3] Number of nursing staff in hospitals surveyed on working conditions, Hospital Nurses Association, (2016)

[4] E. S, Do, M. Y. Kim, Comparison of Internal Marketing, Job Satisfaction and Customer Orientation of Nurses by Size of Medical Care Institution; Small-medium Hospitals and General Hospitals, Journal of Korean Academy of Nursing Administraion ,(2012), Vol.18, No.1, pp.56-66, DOI: 10.11111/jkana.2012.18.1.56

[5] H. J. Kwon, Y. H. Sung, K. S. Choe, H. S. Kim, K. S. Lee, A Study on Verbal Abuse Experienced at Medical Centers, Journal of Korean Clinical Nursing Research, (2007), Vol.13, No.2, pp.113-124, UCI : G704-000921.2007.13.2.004

[6] M. J. Kang, I. S. Park, Types of Violence and Coping Methods Experienced by General Hopsital Nurses, Journal of Korean Clinical Nursing Research, (2015), Vol.21, No.1, pp.92-104, https://doi.org/10.22650/JKCNR.2015.21.1.92

[7] Y. J. Oh, Relations among verbal abuse, job satisfaction, burn out and turn over in nurses working in acute hospitals, HanYang University Graduate School of clinical Nursing, Master's Thesis, (2010)

[8] M. R. Kim, G. A. Seomun, Relationships among Burnout, Job Satisfaction, Organizational Commitment and Turnover Intention to Resign in Hospital Nurses, Korean Jounal of Occupation Health Nursing, (2013), Vol.22, No.2, pp.93-101. https://doi.org/10.5807/kjohn.2013.22.2.93

[9] S. H. Kim. M. A. Lee, Emotional Labor and Communication Competence on Turnover Intention in Nurses, Journal of Korean Academy of Nursing Administration, (2014), Vol.20, No.3, pp.332-341, https://doi.org/10.11111/jkana.2014.20.3.332

[10] M. S. Ahn, Y. J. Lee, The Predictive Factors on Leave Planning of Nurses Working at Medium-Sized Hospital in the Metropolitan Area, Journal of the Korean Data Analysis Society, (2013), Vol.5, No.1, pp.323-334, UCI : G704000930.2013.15.1.008

[11] J. K. Ku, The effect of verbal abuses on casino dealers' burnout, job satisfaction, and employee turnover : focusing on the moderating effect of anger control mechanism, Kyonggi University Graduate School of Tourism, Doctoral Dissertation, (2007)

[12] K. S. Yoon, H. S. Chung, S. Y. Jang, H. R. Kim, H. S. Ohm, Y. H. Sung, K. D. Nam, A Study on the Development of Verbal Abuse Scale for Operating Room Nurses, Journal of Korean Academy of Nursing Administraion, (2005), Vol.11, No.2, pp.159-172, UCI : G704-001792.2005.11.2.002

[13] M. Y. You, Influences of verbal abuse on job stress and organizational commitment of nurses, Chungju National University, Master's thesis, (2011)

[14] C. Maslach, S. E. Jackson, Burnout in organization settings, Applied Social Psychology Annual, (1984), Vol.5, pp.133153.

[15] H. Y. Choi, N. W. Chung, Perfectionism Tendency, Social Support, and Burnout Among Counselors, Korean Journal of Health Psychology, (2003), Vol.8, No.2, pp.279-300, UCI : G704-000533.2003.8.2.003

[16] C. Maslach, S. E. Jackson, M. P. Leiter, Maslach burnout inventory, Evaluating stress: A book of resources, (1997), pp.191-218

[17] J. S. Yoon, A study of violence experience from patients and their families and job satisfaction of emergency department nurses, Department of Clinical Nursing, The Graduate School of Industrial Technology University of Ulsan, Master's thesis, (2004)

[18] D. J.Weiss, R. V. Dawis, G. W. England, L.H. Lofguist, Manual for the Minnesota Satisfaction Questionnaire, Minneapolis, MN, University of Minnesota, (1967)

[19] E. E. Lawler, Perspectives on Behavior in organlzation, $2^{\text {nd }}$ ed, McGwow Hill, (1983), pp.287-301.

[20] H. S. Park, Relationship between Perceived Nursing care role orientation, Job characteristics, and Turnover among Nurses, Gradurate School Yonsei Unieversity, Master's thesis, (2002) 
[21] Y. R. Kim, A Study on the Turnover Intention of the Oncology Nurse, Graduate School, Chonnam National University, Master's thesis, (2007)

[22] H. J. Son, Verbal violence experienced by hospital nurses and consequent emotional reactions and job stress, Department of Nursing Science Graduate School of Sungshin Women's University, Master's thesis, (2010)

[23] E. H. Jeung, S. E. Oh, Violence Experiences, Psychosocial Stress, and Burnout among Emergency Nurses, Nursing \& Health Issues, (2017), Vol.22, No.1, pp.60-67.

[24] K. N. Kang, Factors Influencing Turnover Intention of Nurses in Small-medium sized Hospitals, Journal of Korean Academy of Nursing Administraion, (2012), Vol.18, No.2, pp.155-165, UCI : G704-001792.2012.18.2.002

[25] J. H. Yang, K. H. Jung, Effects of Emotional Labor, Job Satisfaction and Organizational Commitment on Turnover Intention in Nurses, Journal of the Korea Academia-Industrial cooperation Society, (2014), Vol.15, No.12, pp.71707178, https://doi.org/10.5762/KAIS.2014.15.12.7170

[26] H. N. Cho, H. S. Cho, Establishment of a turnover intention model of shift-working nurses in emergency general hospitals, Korean Society of Adult Nursing conference, Korean Society of Adult Nursing, pp.174-174, November, (2016), Korea

[27] J. N. Park, C. W. J, S. Y. Lee, An Empirical Study on the Effect of the OPD Nurse's Verbal Violence Experience on Job Satisfaction and Turnover Intention, Korean Public Management Review, (2017), Vol.31, No.2, pp.227-249, DOI : 10.24210/kapm.2017.31.2.010 